\title{
The Politics of Networked Innovation
}

\author{
Jacky Swan and Harry Scarbrough \\ Warwick Business School, University of Warwick, \\ Coventry, CV4 7AL \\ Email: jacky.swan@warwick.ac.uk \\ harry.scarbrough@warwick.ac.uk
}

Swan, J. and Scarbrough, H. (2005), 'The politics of networked innovation', Human Relations, 58, 7, 913-943. 


\title{
The politics of networked innovation
}

\begin{abstract}
Existing studies suggest that, because knowledge is becoming more widely distributed, innovation increasingly needs to occur 'at the interstices' of collaborating groups and organizations. Networked innovation processes are therefore emphasized, over more hierarchical or market-based forms, as having distinct advantages for the creation and integration of knowledge. Whilst the structural properties of networks have been heavily scrutinized, there is relatively less understanding of processes, in particular the political dynamics that shape networked innovation. This paper aims to develop understanding of networked innovation processes, by identifying and relating the characteristics of networked innovation to the productive, or constraining, effects of different dimensions of power (power of resource, meaning and process). It does this through comparative analysis of three case studies of networked innovation, each involving the development of new technology. This analysis suggests that understanding the politics of networked innovation depends on understanding the generative (and sometimes degenerative) relationship between power, knowledge integration, network formation, and the role of technology. Moreover, the coordination of networks, rather than simply their formation, is found to play a particularly crucial role.
\end{abstract}

\section{Introduction}

A growing body of research now links the process of innovation to network arrangements, within and between organizations (Alter \& Hage, 1993, Powell et al, 1996; Owen-Smith \& Powell, 2004). This research has highlighted the general advantages for innovation of collaborative networked relationships, as opposed to competitive, hierarchical or market-based arrangements (Alter \& Hage, 1993; Hardy et al, 2003). Empirical investigations have investigated a wide range of collaborative arrangements (e.g. consortiums, alliances, joint ventures, trade and 
professional associations, and networks), from a number of different theoretical perspectives (e.g. strategy, knowledge and learning, innovation, network analyses). This literature typically highlights the positive and performative role of networks in relation to innovation, arguing that, innovation is actually more likely to occur 'at the interstices' of collaborating groups and organizations (Carlile, 2002; Powell et al, 1996). Because knowledge, it is argued, is increasingly dispersed across organizational boundaries (e.g. across, professions, organizations, and specialized practices), it is at these interstices, through the operation of networks, that distributed knowledge can be brought together and integrated into new products, processes and services. Thus opportunities for 'networked innovation' are seen as increasingly important to organizational performance, facilitating the creation of new knowledge, rather than just the transfer of existing knowledge (Gulati, 1999).

To date, however, accounts of the interplay between networks and innovation have focused primarily on the structural characteristics of networks (Tidd, 1997, Powell et al, 1996), and have assumed that networks have a fundamentally positive role to play. Fewer studies offer rigorous, empirically based accounts of the processes linking networks to innovation (Oliver \& Ebers, 1998), or consider the potential constraints on innovation posed by network relationships (Barley, 1990). As Hardy et al. (2003) note, this is, in part, because the study of networks in innovation has been dominated by cross-sectional, quantitative studies, using large samples and statistical analyses. This paper, therefore, uses a multiple case study design to explore, in some detail, the processes linking networks to innovation.

A number of processes have been found to be important for networked innovation and could have been the focus of our study - including processes of negotiating and developing collaborative relationships (Ring \& Van de Ven, 1994); forming trust-based relations (Newell \& Swan, 2000); sharing information and resources through formal and informal relationships ; (Conway, 1995) 
generating inter-organizational learning (Inkpen, 1996) and decision-making in networks (Elg \& Johansson, 1997). However, in this paper we focus, in particular, on the role of political factors in the development of networked innovation, following arguments that that this role has generally been neglected and/or under-theorized (Dougherty \& Hardy, 1996; Hardy et al, 2003). Thus, while studies of innovation processes have analyzed the effects of organizational politics on the development of new technologies and ways of organizing, in the main these studies view innovation as being driven by hierarchical, rather than networked, relations (Pettigrew, 1973; Knights and Murray, 1992; Hislop et al., 2000). Conversely, while network studies have examined in detail the ways in which the power and influence of actors, including non-human actors, depends crucially on their relative position in networks (Ibarra, 1993), such studies have only rarely addressed innovation processes in detail. As a consequence, relatively few studies have investigated the political influences on, and political effects of, networked innovation.

In addressing these gaps in the literature, this paper reports on an exploratory study which seeks to contribute to theory-building in this area. The study is wideranging in scope, so as to highlight those factors which are relevant to an improved understanding of the politics of networked innovation and which merit further investigation. The paper itself is structured as follows. It begins with a brief review of the existing literature on networks and innovation in order to define, more precisely, the concept and characteristics of 'networked innovation'. The politics of networked innovation is then posited as a function of the interplay between these characteristics and the productive, or constraining, effects of different forms of power. The paper then investigates this interplay further through an analysis of three case studies of networked innovation, each involving the development of new technology. Through a comparative analysis of these three cases, the paper explores the political dynamics of networked innovation, focusing in particular on: the unfolding of power in the innovation process; the 
influence of networks; the role of technology; and, finally, the implications of the institutional context.

\section{Theoretical Background.}

This section draws from the existing literature to begin to develop an understanding of, first, networked innovation and, second, political influences on networked innovation. In so doing, we have chosen to draw broadly from a variety of different, but overlapping, literatures rather than adhering to a particular, more narrowly-defined research tradition (an obvious candidate being, for example, Actor Network Theory (Latour, 1987). The need for broader, more integrative approaches to understanding innovation and networks has been noted recently by others. For example, Gulati et al. (2000) observe 'the need for coalescing and focusing' research on inter-firm relationships (p.204). Similarly Hardy et al (2003) note the problems of fragmentation in the current literature and highlight 'a need for a broader approach to studying collaboration' (p. 322), that takes into account, for example, the strategic, knowledge creation and political effects of collaboration. Accordingly, we adopt a more comprehensive approach than much of the existing work on innovation and networks, the aim being, not to develop an all-encompassing theory (likely an impossible task (Wolfe, 1994)), but, rather, to promote the development of mid-range theorizing on the relationships between political processes, power and networked innovation - relationships that can then be explored, and further refined, through our empirical analysis.

\section{Networked innovation}

The term 'networked innovation', as employed here, denotes a distinctive category, or type, of innovation processes. Whilst previous studies hypothesize that this type is increasingly important (e.g. Powell et al., 1996) the idea of 
networked innovation has been deployed in a wide range of ways in the literature to date. To focus our discussion then, and following Hardy et al's (2003) definition of collaborative processes, we define networked innovation as 'innovation that occurs through relationships that are negotiated in an ongoing communicative process, and which relies on neither market nor hierarchical mechanisms of control' (cf. Phillips et al., 2000).

This definition distinguishes networked innovation from innovation processes that are driven primarily by hierarchical and/or market-based mechanisms (e.g. innovation in supply-chain relationships or top-down organizational change initiatives). It also distinguishes networked innovation from the broader concept of collaboration in Hardy et al's account. Whereas the latter focuses on all interorganizational relationships (including networks, but also joint ventures, alliances, associations, consortiums) that are collaborative, here we focus on relationships where the specific purpose is innovation. Moreover, our definition encompasses both intra- and inter-organizational relationships, and competitive as well as collaborative relationships. This is an important departure from Hardy et al's (2003) account, since it recognizes that, in the context of innovation, the boundaries between inter-and intra-organizational relationships are often blurred, with, for example, intra-organizational boundaries (e.g. across departments) sometimes being more sharply defined than relationships across firms (for example, between innovating firms and change agents (Gittell and Weiss, 2004; Sturdy, 2004). Moreover, this approach to networked innovation reflects the view that competitive relations (for example, between business units that compete for central resources) can be just as important in shaping networked innovation as collaborative relations, by generating divergent agendas and resistance to change (Elg \& Johansson, 1997; Alter \& Hage, 1993).

\section{Characteristics of networked innovation}


The different strands of the literature which deal with networked innovation have identified a number of defining characteristics of such innovation which are relevant to our study of political dynamics. These characteristics include; the importance attached to mechanisms of knowledge integration; the critical part played by social networks; and the pervasive role of technology.

First, in a number of studies the development of networked innovation is seen as highly dependent on the integration of knowledge from diverse sources. Views as to the mechanisms of integration tend to diverge depending on the definitions of knowledge employed (Okhuysen \& Eisenhardt, 2002). Writers adopting a 'content' view of knowledge tend to define integration as the 'combination' of different bodies of explicit knowledge (Nonaka \& Takeuchi, 1995). Others, however, with a 'relational' view (Scarbrough, 1996), place greater emphasis on the development of shared understandings and boundary spanning activities as a pre-requisite of integration (Boland \& Tenkasi,1995). For example, in the context of intra-organizational innovation (cross-functional) in engineering, Carlile (2002) identifies the need to overcome boundaries based on differences in language (syntactic boundaries), understanding (semantic) and practice (pragmatic).

Second, networks of many different kinds have been implicated in recent research as playing a central role in the development and implementation of innovations (Hansen, 1999) Thus, the role of formal organizational networks is frequently seen as subject to reinforcement by informal, or inter-personal, networks (Jones et al., 2001; Grandori and Soda, 1995; Conway, 1995; Kreiner and Schultz, 1996). In summary, and without reviewing this extensive literature in depth, the contribution that these studies make to a political analysis of innovation is to identify the major structural and processual aspects of networks influencing processes of innovation.

Thus, from a structural point of view, networks are seen primarily as communication channels through which knowledge is disseminated (Rogers, 
1983, 1995; Owen Smith \& Powell, 2004). Networks are seen as performing a boundary-spanning function, enabling the transfer of knowledge across organizational and inter-organizational boundaries (Conway, 1995). Summarizing, important features of network interactions in the context of innovation have included: (i) the strength (shallow, deep) and scope (narrow, broad) of social ties within the overall network (Alter and Hage, 1993; Granovetter, 1973; Hansen, 1999); (ii) the level of interaction - interpersonal (links among particular individuals within or across organizations), intraorganizational (links within organizations at the organizational level, e.g. crossfunctional teams), inter-organizational (links across organizations at the organizational level, e.g. formal alliances - Oliver and Leibeskind, 1998); and (iii), the direction of information flows in the network - unidirectional (from one member node within the network), bi-directional (between nodes), multidirectional (across multiple network nodes - Alter and Hage, 1993). This perspective delineates, therefore, the patterns of interactions among network partners and relates these, both to the forms of knowledge which can be exchanged, and to political effects on partners. Thus interpersonal networks, involving deep, trust-based relationships have been seen as more appropriate for the integration of tacit forms of knowledge (Oliver and Liebeskind, 1998). Conversely, inter and intra-organizational networks based on weak/shallow ties are found to be more effective for the integration of explicit forms of knowledge (Hansen, 1999).

Complementing this structural view are those studies which highlight the processes of network development and formation (Smith-Ring, 1997). In this account, the networks involved in innovation are dynamic, evolving and emergent (Powell et al., 1996). For example, Ring and Van De Ven (1994) propose a cyclical model of network formation, encompassing four distinctive activities taking place amongst networks partners - negotiations, commitments, executions, and assessments - each playing generative role in the development of further network relations. Likewise, in their study of network development in 
R\&D, Kreiner and Schultz (1993) show how networking activity crystallizes new network relationships which then act as a 'centre of gravity' for further networking and innovation.

The contribution of this processual view is particularly valuable to a political analysis inasmuch as it highlights the ways in which network partners learn, adapt and re-evaluate their roles and commitment, as a response to prior experiences of working together. It also highlights the importance of considering discursive practices through which relationships and ideas come to be communicated and negotiated (Swan et al, 2003). An important feature of such negotiation concerns the basis of network formation. For example, Hardy et al (2003), in their study of collaborations in small Palestinian NGO, were able to distinguish relationships that were primarily based on transactions (where resources are pooled or transferred but new coalitions do not emerge), partnerships (where partners work together to carry out new activities) or representations (where partners work together and represent each other's interests to outside parties). They found that collaborations that were based on representations were more likely to have political effects, in the form of increasing the influence that partners had over the development of further interorganizational relationships. In relation to innovation, both partnerships and representations were linked more strongly to knowledge creation effects (referring to the creation of new knowledge that collaborators did not previously possess) than transactional relationships. In this perspective, then, networks are seen as important, not only as channels for the transfer of knowledge, but also as vehicles for the creation of new knowledge through a process of collective 'sense-making' (Ring \& Van De Ven, 1994; Orlikowski, 2002).

Developments in social theory (for example, Castells, 1996) have highlighted the pervasive role of technology, and particularly information technology (IT), in the development of networked innovation. Work at a more micro-level too has highlighted the mutuality of technological development and organizational forms 
within the innovation process (Orlikowski, 1992). According to this view, networks play a crucial role in communicating and negotiating which, and whose, understandings and interests (or 'technological frames') come to dominate innovation processes. Taking this further, McLoughlin et al. (2000) note that technology, and, correspondingly, technological innovation, should be seen as 'part of a broad 'socio-technical ensemble' or 'network"', arguing that 'in this approach the political and social nature of technological change is revealed [...by] focusing on competing accounts ('interpretive flexibility') of technology and its effects in contexts that shape these accounts. (p. 19).

In summary, this review highlights a number of the characteristics of networked innovation which may be relevant to understanding its political dynamics. These include: the forms of knowledge involved and the mechanisms of integration; the contribution of network structures, and the processes of network formation, to negotiations amongst actors; and the role of technology (and associated networks) in framing innovation processes.

\section{The politics of networked innovation}

In taking these insights forward to develop a political perspective on networked innovation, we need to recognize some important limitations in the existing literature. The majority of studies in this field have tended to focus on the more overt forms of political influence, including, the role of managerial coalitions, political tactics and the micropolitics of self-interest amongst decision-makers (Pettigrew, 1973; Brass \& Burkhardt, 1992; Jones et al., 2001). The emphasis has been on the ability to develop power over other groups, through the mobilization of resources (for example, financial resources, information, and staff). The negative connotations of a focus on hierarchically coercive power have tended to steer research on innovation away from deeper analysis of the dynamics of power (Hardy, 1996). 
From our above account, however, this concern with the exercise of power in hierarchical settings has limited applicability to innovations (e.g. multi-site innovations) involving complex networks of actors both inside and outside of the focal organization that cannot be driven through coercive means. Hence, in this paper, we adopt a more neutral view which is able to acknowledge power as a productive force, independent of hierarchical settings. In short, we recognize power as 'a force that effects outcomes, while politics is power in action' (Hardy, 1996, p. S3). This definition allows us to address 'power to' as much as 'power over' (Townley, 1993; Foucault, 1980). This widening of the scope of political analysis also draws attention to factors beyond the immediate confines of particular innovation processes - specifically, to the wider context within which such processes unfold (Powell et al. 1996).

The existing literature on power is clearly too extensive to be adequately summarized here. In analyzing the politics of networked innovation, however, it is important to recognize the different forms and sources of power which may be exercised. In a review of the literature on power in situations of strategic change, Hardy (1996), based on Lukes (1970) original conception of the multidimensional nature of power, usefully summarizes three different dimensions. These are labeled as power based on resources, processes and meaning, respectively. In the first dimension - resource power - 'power is exercised by actors to influence decision outcomes and bring about the desired behaviour through the deployment of key resources on which others depend' (S7). In the second, the process dimension, 'power resides in organizational decision making processes which incorporate a variety of procedures and political routines....preventing subordinates from participating fully in decision-making.' (S7). And in the third dimension (Lukes, 1974), meaning power operates through the semantic aspects of organizational life, involving the legitimation or de-legitimation of particular activities. 
This framework provides a useful heuristic to apply to the politics of innovation. As Hardy (1996) notes, the three dimensions involve different sources of power and different ways of exercising power. Linking these dimensions to the previous discussion of networked innovation suggests a number of different possible effects. For example, in relation to knowledge integration, the resource dimension suggests that in those situations where knowledge is in the possession of a particular group or individual, dependencies are created amongst other groups (Pettigrew, 1973). Second, the formation of social networks may shape the distribution of resource power and process power by creating new patterns of interdependencies between groups (Hickson, 1971). The process dimension highlights the political importance of knowledge being embedded in decision-making routines, and its implications for the inclusion or exclusion of particular groups (Dawson et al, 2000). Process power may be seen, then, as a product of an actor's particular position in the network and their ability to act as 'obligatory passage points' in the decision process (Callon, 1980). For example, research has highlighted the importance of occupying not only the central positions within networks, but also the 'in-between' or boundary spanning positions, for the accumulation of power (Brass \& Burkhardt,1992; Ibarra, 1993). Network formation is important in shaping the informal channels through which individuals and groups access decision-making arenas (Macdonald, 1993). Likewise, involvement in decision forums opens possibilities for shaping the further formation of networks. For example, in a study of UK professional association for production management, consultants were able to shape the formation of the professional association network by involving themselves in decisions regarding the educational programmes it offered (Swan et al., 1999).

Finally, the meaning dimension highlights the interdependence of power with the shared meanings developed within social communities (Brown and Duguid, 1991). The latter involve, as Lave and Wenger note, 'an activity system about which participants share understandings concerning what they are doing and what that means in their lives and for their community' (Lave \& Wenger, 1991: 
98). Network formation is important here in developing shared practice and, hence, shared meanings (Brown \& Duguid, 2001; Carlile, 2002). The tacit forms of knowledge arising from practice are seen as embedded within a common understanding or a common frame of reference. In network terms, the power of meaning highlights the role of networking as a process of interrelating and sensemaking amongst social groups (Senker \& Faulkner, 1995; Weick, 1979).

As applied to our empirical analysis, adopting a broad view of power as a productive force suggests focusing on the linkages between the three dimensions of power and the characteristic features of networked innovations outlined above. Whilst this paper aims, primarily, to identify the ways in which these forms of power are systematically related to innovation processes (i.e. as both medium and outcome), we also acknowledge the importance of the wider institutional context in which networks are embedded.

\section{Methodology}

The research design deployed qualitative analysis in three cases of networked innovation. Multiple cases provide rich data and searching for patterns across these data can help theory development around complex social phenomena, as appropriate to this exploratory study (Eisenhardt, 1989). The unit of analysis was the innovation process, and not the organization. This was deemed appropriate, given that networked innovation can encompass relations at both intra and interorganizational levels and, as seen, the boundaries across these levels in often blurred (Gittell and Weiss, 2004). The cases were conducted as part of a larger cross-sector, longitudinal study of the role of networks in technological innovation ${ }^{1}$. The three reported here were chosen because they provided the

\footnotetext{
1 We are grateful to the UK Economic and Social Research Council (ESRC) for funding this research. We would also like to acknowledge the Prof sue Newell and Dr Donald Hislop for their contribution to the original research project that generated the cases used here. Pseudonyms have been adopted for the collaborating firms to protect their confidentiality.
} 
best examples of networked innovation, as defined above (other cases being driven by hierarchical relations). Given the exploratory nature of our research, the cases were chosen so as to reflect points of comparison, as well as contrast, which could facilitate identification of meaningful patterns in the data (Yin, 1994).

Our study aimed to analyze power from a broad perspective, encompassing the different dimensions outlined above, which were seen as embedded in wider institutional arrangements. Therefore, the first point of contrast was to examine cases of networked innovation across different sectors (financial, manufacturing, health). The aim here was not to systematically compare sectors (three cases would hardly be sufficient for this), but, rather, to provide variation across contexts so that we could gain some insights in our analysis into the extent that macro institutional arrangements might be important in mediating micro-level politics (the primary focus).

A second variation was in terms of the technologies being implemented in our cases. As seen above, interpretations of technology (technological frames) have been found play an important role in shaping political processes and in negotiating order within innovation contexts (Orlikowski and Gash, 1994). These frames are shaped, both by cognitive and social experience, but also by the technology itself (McLoughlin et al., 2000). Therefore, variation here could provide interesting insights into the interplay between technology and political influences on networked innovation. A third point of contrast (a posteriori) was the 'success' of the innovation process (at least, in relation to the targets set by the core group attempting to manage it). An important feature of process research is that it attempts to link variation in effects with characteristic features of a process. The aim here is not to develop generalized, prescriptive accounts (for example, about the management of networked innovation) but, rather, to look for patterns across cases that may offer some explanatory value (Pettigrew, 1987). Where similar patterns can be observed, in the face of variation across 
cases, then these are likely to reflect phenomena of real interest in relation to theory development on the politics of networked innovation.

In terms of comparison, our cases represent examples of networked innovation in relatively large (at least 3400 staff) multi-site, multinational firms (the focal organizations), which were attempting to increase their respective market shares by the introduction of innovation in the delivery of products and services to clients (in the case of the healthcare firm, this included clinicians and patients). All three focal organizations were structured around geographically-dispersed business units and, in each case were characterised by a strategy of growth through acquisition. This meant that local business divisions were used to operating with a high degree of local autonomy. In each case, the innovation projects were aimed at designing, and rolling out, a more standardized delivery of products and services across regions. In the case of Bankco, this involved the development and roll-out of a global intranet for 'Knowledge Management' (their terms). In the case of Liftco, it involved the development of a common Enterprise Resource Planning System for sales support. Finally, in the case of Healthco, it involved the development and roll-out of a standardized technique for delivering a new form of therapy for prostate cancer by encouraging the establishment of 'Centres of Excellence' in hospitals. In all cases, the actual design of the innovation was complex, both in terms of the organization and technologies involved, and it required input and expertise from the different social groups at which it was targeted. Thus, in all cases, the knowledge relevant to innovation process was widely distributed (across functional departments, professional groups, business units, and corporate staff), but in no case did the core team, who were attempting to manage the innovation process, enjoy significant hierarchical power over these groups.

In order to better understand process, real time data collection was coupled with retrospective accounts. Thus, each case involved a minimum of 3 fieldwork visits (on average, 4 days) over a period of 2 years in order to conduct interviews with 
key individuals involved at that time. These included project managers, other members of the project management teams, technical support staff, and any other individuals deemed to be providing core expertise or support including end users and, where possible, external consultants (used in all cases). Given the networked nature of the innovations, it was impossible to identify interviewees a priori - individuals became involved as networks developed. Therefore 'snowball sampling' was used to identify interviewees on each visit (Biernacki, 1981). In total, 78 semi-structured interviews were conducted (an average of 7 per visit in each case, the additional interviews being with individuals not located at the main fieldwork sites). All except three (in HealthCo) were face-to-face. Interview data were supported by documented evidence (e.g. project reports, training materials, web-materials) and participant observation whilst on site. In the Bankco case it was also possible to attend a 2-day international workshop aimed at involving business managers in the innovation process.

A central goal of this study is to aid theory development through multiple cases. To achieve this, our analysis first provides a brief summary of each case, but then focuses on cross-case comparison linking characteristic features of networked innovation (knowledge integration, network formation, the role of technology) and the dimensions of power, outlined above. This approach has been used elsewhere, to good effect, as an alternative to more traditional qualitative accounts based on extended narratives (Hardy et al, 2003). This approach, being based on categories identified in the literature, also helps to reduce subjective bias in the filtering of information and enables comparative analysis based on within-group similarities and differences (Eisenhardt, 1989).

\section{Case Summaries}

\section{Liftco.}


Liftco was one of the largest European manufacturers and sales/service providers of materials handling equipment (e.g. fork lift trucks), organized into 12 highly decentralized national business units, with a headquarters in Sweden. Liftco's Sales Support Project (SSP) was launched in response to a corporate study of business processes which pointed to a need to improve co-ordination across the sales/service businesses. A major vehicle was the introduction of a common information management and planning system - an ERP (Enterprise Resource Planning) system. The corporate IS (Information Systems) function, which was charged with its implementation, was a small group of only 9 employees that had little material resource or formal authority over national business units. Further, there was no 'off-the shelf' software available at the time that could handle Liftcos' multi-site, multi-national functionality needs. Therefore, a new system needed to be designed incorporating local knowledge of existing practices across functions and regions. However, given the system would impose greater standardization on management practices at local levels, the potential for resistance was high. A major political challenge therefore centred on the tradeoffs between local autonomy, and standardization from the Centre.

In addition, Liftco faced the problem of integrating business knowledge with specialized ERP technical expertise. To resolve this, management engaged an ERP software supplier and consultancy - Consultco. The choice of supplier was made, not on the basis of cost or promised functionality but, rather, because it was felt that a 'truly' collaborative partnership would be easier to establish with Consultco (a small, Swedish supplier) than its competitors. The idea was that Liftco would benefit by having a system tailored to its needs, and Consultco would benefit by being able to use Liftco as a reference site for the new version of its software. The Project Manager at Liftco also knew Consultco well, having been to university with one of its senior consultants. To reinforce the partnership, Liftco and Consultco developed a unique employment contract with new graduates recruited into Consultco to work on the SSP project. This allowed them to choose employment with either Consultco or Liftco following project 
completion. This novel employment contract gave these Consultco consultants the dual incentive to acquire knowledge of the Consultco software and LiftCo's operating context.

The SSP project involved 2 main phases - initial design and implementation. In the first, 6 senior managers representing different regions and functions within the business, were invited to join with Consultco consultants and the corporate IT group for a 3-week period to scope out the initial design. At the same time the SSP project manager traveled around the regions to present an outline of what the SSP project (captured in a brief Powerpoint presentation) could deliver to local businesses. In the second phase an SSP core team was assembled to guide implementation, and further specify the system design. Members were persuaded to join the team, not only from the corporate IT group, but also from different functional areas and regions. Selections were made on the basis of 'personalities' (e.g. were they 'dynamic', 'participative') as much as technical expertise. They were divided into three subteams, each handling (initially) three implementation sites. The Dutch site, though small in business terms, was scheduled as the first to go 'live' since it was anticipated that successful implementation here would ease resistance from the larger, more powerful French and UK sites. Each implementation team comprised, on average, 9 people including a Consultco consultant, a member of the corporate IT group, and local business managers who (where possible) were those that had been involved during the design phase. The implementation teams were trained together and continued to meet all together throughout on a tri-weekly basis. This was felt to be important in establishing a shared understanding of the ERP system and in creating an informal, social network that teams could draw upon as a collective problem-solving resource. This network was reinforced through intensive IT-based communications, eventually giving rise to a web-site which allowed individuals both within and beyond these teams to share experience via 'frequently asked questions'. The project was completed within a month of its target date, with the ERP system being implemented across several businesses. 


\section{Bankco.}

Bankco was a large European bank, operating across 70 countries. Its structure was highly decentralized, comprising a number of national business units together with a range of product divisions and a small corporate function at the centre. In the mid-1990's a major global client withdrew its account because it did not feel that it was receiving a uniform quality of service across countries. Bankco responded with a paper written by members of the corporate business strategy committee, recommending that Bankco develop a global 'Knowledge Management' (KM) strategy (their terms) to encourage knowledge sharing across all of its business divisions. A centre-piece was to be the implementation of a global Intranet, and in consequence the project was handed over to the corporate IT group. This group had resources to fund hardware development. However, the decentralization of resources within the bank meant that investments in software, content development and training needed to be sought at business unit level.

An international workshop was held at the corporate headquarters to 'kick-off' the project, bringing together IT experts from a number of different divisions. At this, a pilot intranet was demonstrated in order to raise awareness of the role of Intranet technology in enabling $\mathrm{KM}$. These experts were enthused about the possibilities of the new technology and many, when they returned to their different business units, began developing their own Intranet system utilizing locally provided resources, including their own local consultants. The most enthusiastic came to be known as 'hobbyists'.

Whilst the innovation was proclaimed as a 'KM' project, there was little actual attention given to the development of collaborative arrangements or coordinated meetings across business units, subsequent to the one-off pilot workshop. One direct consequence of this lack of ongoing collaboration was a failure to establish further formal or informal networks capable of linking individuals (including IT experts and Business managers) across different businesses. For example, a 
number of different divisions began to experience problems with the same IT consultants at local level, unbeknown to one another. Businesses facing different market demand also had different interpretations of the capability of a global intranet. Thus, whilst the Global Services Division (dealing with Global customer accounts) was keen to collaborate further on its development, the Domestic Division (who dealt solely with personal accounts) did not see a Global KM strategy (or global intranet) as particularly relevant to their needs. Meanwhile the Domestic IT division was keen to experiment with the programming language, so developed its own intranet. This was seen as being 'all singing and all dancing' in terms of technology but had very little business-relevant content.

The outcome of these scattered endeavours was numerous independent intranet projects being started almost spontaneously, supported by local funding and 'hobbyists'. Within 3 years an estimated 150 intranet sites had been developed (although the precise number was not known to senior management), each with its own 'look and feel' and with few, if any links, between them. Recognizing this, the corporate IT group held a second, 2-day, international workshop that brought together local IT specialists with business line managers. The aim was to integrate business knowledge into the design of common portal that would connect the various intranets. However, this was not particularly effective because an argument broke out amongst the participants about the financing of this portal. Further, many of the business managers left after business needs were discussed on Day 1. This meant that the actual design was decided on Day 2 by a remaining group, of now mainly IT experts, who focused on technical rather than business requirements.

\section{Healthco:}

Healthco was a large multinational biosciences company with a major part of its business devoted to the manufacture and delivery of imaging products for medical diagostics (e.g. radioactive isotopes for the diagnosis of cancer). It's European business comprises geographically dispersed divisions with high 
degrees of autonomy. The Prostate Cancer Therapy (PCT) project began as a small 'spin-off' to develop and market Healthco's 'brachytherapy' products. Put simply, brachytherapy involves the implantation of radioactive iodine seeds directly into a prostate (in this case) tumour to kill cancer cells from within. The PCT project was headed by a Vice President of Global Manufacturing who handpicked, a small multidisciplinary (clinical, scientific, manufacturing, and commercial) team in the UK. Individuals were chosen on the basis of their ability to represent diverse areas of interest (e.g. one scientist had been a General Practitioner for 10 years).

Whilst brachytherapy had been around for some time, Healthco had recently developed a new technology that allowed more accurate seed implantation and improved clinical trails effectiveness. Delivery of brachytherapy, as a treatment, also entailed significant organizational innovation. Traditionally prostate cancer had been treated with prostatectomy (surgery by a consultant urologist), often followed later by radiotherapy. Since brachytherapy combined surgical skills (for implantation) with radiotherapy (for dosage), it represented a radical departure from this established practice, requiring consultant urologists and radiologists, as well as nurses and physicians, to be involved in all stages of treatment decision and delivery. This shifted primary authority for patient treatment decisions away from the consultant urologists - the most powerful of the professions involved. A major political challenge, then, was to overcome resistance of professional groups - especially urologists, whose collaboration and expertise was essential in order to further design, prove and develop the brachytherapy treatment. In addition, medical therapeutics represented a major departure from Healthco's, long established, diagnostics imaging business. As a result, the PCT project was not recognized within the mainstream structure of Healthco - being described as an 'orphan project' - and the UK team had no formal authority over the divisional managers or sales staff. 
In this context, the strategy of the UK team centred on raising awareness of the prostate cancer disease, and brachytherapy as a treatment, rather than promoting their particular technology. An important part of this was to develop a 'community or care' around brachytherapy innovation. Thus, in the words of the project leader, the PCT project was about 'collaboration, creating communities, engagement and cooperation, enabling choice of treatments both by the doctors and the patients'. This discourse of 'collaboration' and 'community of care' was used to frame the team's activities in promoting brachytherapy amongst professionals groups outside Healthco and managers in the regional businesses. In particular, it appealed to personal aspirations to become involved with the first Healthco product targeted at patient cure rather than just diagnosis.

The PCT team's activities were multi-fold. First, they assisted hospitals in establishing 'Centres of Excellence' where multidisciplinary teams could treat patients using brachytherapy techniques and where other professionals could be given 'hands-on' training. Second, most of the budget went to developing training and education materials for medical professionals and Healthco sales people. Third, specific events were organized to raise awareness amongst the medical communities about the innovation. Key opinion leaders were identified and cultivated to address such events, and speak on behalf of the therapy's success. One such event invited senior medical professionals across disciplines to a weekend meeting to discuss brachytherapy possibilities. Significantly, this led this group to establish their own professional network aimed at identifying common treatment standards in Europe. Finally, information flows were actively managed. For example, a web-site (under Healthco's editorial discretion) provided educational material on brachytherapy treatments (including Healthco's) and a public relations firm was contracted to educate public opinion on the disease. One scientist was responsible for abstracting material from scientific articles to disseminate to the wider community of salespeople and professionals. To counter the dangers of the 'isolation' of the innovation project within Healthco, informal, interpersonal networks were used extensively. This helped, for 
instance, to elicit knowledge from Healthco's USA subsidiary on the development of the innovation there. These activities were largely successful in overcoming overt resistance and number of new hospital centres were established. Within Healthco, a separate therapy division was established, eventually going into partnership with a cancer specialist firm to form a new company.

\section{Analysis and Discussion}

In reviewing the cases, this section focuses first on a comparison of the three cases in order to relate the characteristics and outcomes of the innovation processes to the different dimensions of power described earlier. Next, it considers the political implications of technology for networked innovation processes. Finally, drawing from the Healthco case, we comment, albeit briefly, on the implications of the wider institutional context for networked innovation. Throughout, the aim is to develop a processual account of the interplay between networked innovation, power and politics.

Table 1 compares the three cases along the key dimensions of power and networked innovation (knowledge integration, social networks, and the role of technology), as identified from our earlier literature review. Of course, while this is useful for comparative purposes, it is essentially a static representation. Therefore, the networks represented in Table 1 are those, in each case, that were dominant in shaping innovation processes. We also need to recognize that the different dimensions of power (resource, meaning, process) are experienced differently from different standpoints. Table 1 , then, refers primarily to power from the standpoint of those who had particular interests in promoting the innovation rather than preserving the status quo. At the outset of the process, this refers to the project management teams.

Insert Table 1 here 
In all cases, the innovations (ERP, Global KM, Brachcytherapy Centres) needed to be designed and modified as they were implemented, incorporating knowledge distributed across disparate groups (i.e. across specialist functions and divisions in Bankco and Liftco; across business divisions and medical professions in Healthco). Yet, as Table 1 shows, there were clear differences in the extent to which firms were able integrate this distributed knowledge into the innovation process. Knowledge integration was higher in Liftco and Healthco, than in Bankco, despite Bankco's explicit agenda for knowledge sharing. This is not to say that there was no innovation in Bankco - there were numerous examples of intranet development, at local level, with many combining expertise of 'hobbyists', locally appointed consultants, and local managers. The issue here was that this knowledge was not integrated into the intended innovation of Global KM.

Relating this to the role of networks, a key omission in the Banko case was the inability of the core management team to develop collaborative relations and commitment to the innovation across the disparate businesses. The basis, or rationale for network formation, appeared to be important here. In Liftco this hinged on the formation of partnerships (between the core team and the national businesses, and between the Consultco consultants). In Healthco, representation - where collaborators would represent one anothers' interests in brachytherapy was the primary basis for network development. Finally, in Bankco the exchange of resources (i.e. financial resources from the businesses to further fund the global intranet) was the primary motivator. As Hardy et al (2003) proposed, our findings indicate that relationships based on representation and/or partnerships were more likely to generate positive effects on knowledge creation than those based primarily on the exchange of resources.

A second major factor in relation to network development - and an important finding from this study - concerned the importance attached to the coordination of network activities. This, as Table 1 indicates, seemed be more important in these cases than the breadth of networks relations formed or the direction of 
information flows - for in all cases an expansive range of groups were involved, at various points both within and outside the organization, and information flows could be described as multidirectional (Alter and Hage, 1993; Hardy et al, 2003). Rather, it was the ability of the core teams to co-ordinate network relations such that they coalesced around their intended innovation (Gitell and Weiss, 2004) which seems to have been critical. In both Liftco and Healthco, for example, the solution to coordination entailed the development of networks to generate further networks centred on the innovation process. Thus, in each case, a project team was created that reflected the different interests of the specialist groups involved (e.g. with members from different functions and national businesses in the Liftco case, and with members that had scientific, medical and commercial experience in Healthco). Crucially these initial groupings (including the external consultants in Liftco) were selected, or (more accurately) persuaded to join the teams primarily on the basis of informal, interpersonal links with the project manager. This helped to develop strong ties such that, despite coming from different backgrounds, these teams were able to develop common understandings and practices that allowed them to integrate their knowledge. This echoes earlier research highlighting the importance of informal, interpersonal relations in the nascent phases of innovation (Kreiner and Schultz, 1993; Oliver and Leibeskind, 1998).

These common understandings led to the development of more codified 'templates' for innovation (e.g. initial design specifications in Liftco, and the centres of excellence in brachytherapy model in Healthco (Clark and Staunton, 1989). Training, educational events and materials, underpinned by these templates, were then used to enroll a wider community into the further reconfiguration and 'proving' of the design concepts. At the same time, the information flows were orchestrated by the core teams. For example, in Healthco, educational events and information, coordinated by the Healthco team, promoted debate and discussion around the brachytherapy treatment. In turn, the shared experience of training and implementation of the innovation, helped to promote 
the development of new social networks which made it possible to develop further collective understandings and, hence, the wider exchange of knowledge across contexts. For example, in Healthco, debates amongst medical professionals around brachytherapy (held at the weekend meeting which was organized by Healthco), stimulated the development of a new, cross-professional network to oversee the specification of new standards on the treatment that were agreed collectively by the different professions involved. Thus, the reach of coordinated action was progressively expanded, enabling more effective implementation of the innovation, despite potential resistance.

Conversely, in Bankco, this generative relationship between networks and knowledge flows failed to develop. Here the notion of integrating knowledge was not reflected in the development of appropriate collaborative arrangements to allow shared practice. Instead, the focus was placed on a discourse of 'Global KM' and a technology which was widely available across different sites. In the absence of social networks across different business units, and any shared commitment to, or understanding of, the Global KM vision, knowledge integration activities were directed by technology enthusiasts (hobbyists) towards localized interests and concerns. Coordinated action thus collapsed to the level of the individual business unit and disintegration of knowledge was the result.

These findings suggest, then, that considering the coordination of different kinds of networks (both intra and inter-organizational) and the ways these shape knowledge flows, might provide a better explanation for their effects in relation to innovation, than considering the formation of particular networks or their discrete effects. Thus, much existing work looks, either at the characteristics and effects of networks (i.e. from a structural perspective, Hansen, 1999), or at the formation of network relations, (i.e. from a processual perspective), with studies focusing on particular network types (e.g. inter, or intra-organizational - Hardy et al, 2003). Whilst this has been useful in our analysis, our cases, suggest what is critical to networked innovation is the co-ordination of networks at different levels 
(interpersonal, intra-organizational, inter-organizational) throughout the innovation process, and the processes through which one set of relationships can be used to trigger the development of another. As Gittell and Weiss (2004) note, 'frameworks for analyzing organizational phenomena must be responsive to the dynamic and complex characteristics and inter-relationships between multiple levels of analysis that 'real life' situations reflect'..

Turning to political factors, the case comparison (Table 1) suggests that these systematically shaped both the formation and co-ordination of networks and the outcomes of the innovation process. In terms of outcomes, in Liftco the ERP project team succeeded in overcoming the resistance from national business units and functions to the standardization of systems and practices. In Bankco, by way of contrast, the KM project was successful in stimulating awareness of Intranet technology and intranet development at local level, but was unsuccessful in securing overcoming business unit boundaries in its ambitions of global knowledge sharing. In Healthco, the PCT project was successful in promoting the brachytherapy innovation against professional resistance and in getting the Healthco product recognized within its own business. Activity here involved supporting new social networks and collaborative processes within a discourse of 'community of care'

Turning now to the different dimensions of power, we can make the significant observation that in all of our cases project teams enjoyed little resource power. At both Liftco and Bankco, the corporate centre was relatively weak and exercised little influence or resource power over subsidiary organizations. At Healthco, the project team's position power was even more marginal, with little support from senior management, no formal authority over regional managers, and limited material resources to fund their activities. In none of the three cases, then, could the networks or knowledge flows (outlined above) be directly controlled by project managers. Ciborra (2000) notes tendencies towards either 'drift' or 'control' in innovation processes comprising changes in organization and 
technology. Relating to this, the project management teams in both Healthco and Liftco, could be seen as deploying power as a productive force to mitigate these tendencies. In contrast, in Bankco drift emerged as the stronger force, with activities occurring more or less spontaneously across the businesses. The experience in these cases thus highlights the importance of 'power to' (encompassing both process and meaning power) rather than 'power over' as the critical factor in determining the outcome of innovation processes.

Taking Liftco as the first example, we can observe the use and development of process power in the careful selection and enrolment of members into the design and implementation teams. Individuals were selected into project teams on the basis of creating representation and participation as much as by their technical competencies. Likewise, Consultco was selected, not only on the grounds that it provided the necessary technical expertise, but also because, as a Swedish company, its interests were seen as more likely to be aligned with Liftco. Thus, the partnership arrangement with Consultco supported the development of informal networks between the firms. Here, the Consultco graduate consultants played an important role as 'brokers', bridging the social communities of LiftCo and Consultco.

More generally, in this case, the careful selection of the core project team's members endowed it with significant access to social networks across the company. This, in turn, was amplified by the informal linkages created across the local implementation teams through training and regular meetings.

These collaborative arrangements progressively included certain groups and individuals and helped to create new social networks through which knowledge could be elicited and applied. As a consequence, the core team benefited from the network centrality which they enjoyed within these new relationships (Ibarra, 1993), so increasing their social capital and power. As Galaskiewicz (1979) notes, organizational power is not so much a function of control over material resources but rather accrues from 'the set of resources that actors mobilize 
through their existing set of social relationships' (p. 151). Moreover, such networks operated, not only as channels for the communication of knowledge, but also as communities through which meanings could be created and shared. Here, the power of meaning was especially important. In particular, the system was framed, not as an ERP system, but as a 'Sales Support Project', linking it to shared values of coordination and local autonomy. This helped to veil the standardization objectives of the system and to legitimize and gain its acceptance across the different business units of the firm.

Turning to the Healthco case, here again, as with Liftco, process power specifically via the solicitation of team members within the firm and the cultivation of 'opinion leaders' outside it - was important in the formative role played by the collaborative arrangements of team-working and Centres of Excellence. The Healthco team also benefited from some degree of centrality in the relationships created by these forms of coordination. This was an important counterweight to their relatively marginal position within the Healthco business, internally. However, whereas the project team at Liftco were able to argue explicitly for business objectives (efficiency through sales support) as a way of framing the innovation, in Healthco such an approach would have been counter-productive to the establishment of inter-professional networks externally. For example, there was general suspicion amongst medical professionals of any activities deemed to be driven by a commercial agenda. Indeed this was a key reason why, following the Healtho weekend event, the medical professionals involved decided to set up their own, independent forum for specifying professional standards. Process power was, therefore more limited, centring on the ability of Healthco managers to manipulate information flows through, for example, the development of training and educational materials, the cultivation of scientific experts as opinion leaders, and the employment of a Public Relations company.

In the face of a relative lack of process power then, in this case power of meaning was particularly crucial. The particular strategy here was the framing of 
the innovation, not in terms of Healthco's own product, but in terms of the importance of curing prostate cancer disease by considering brachytherapy as a treatment. The discourse of 'community of care' was particularly important here in legitimating new forms of coordination and knowledge integration both within and outside Healthco, and in re-presenting commercial goals as medical goals (a more detailed account of this aspect of the case can be found in Swan (Swan et al., 2002). Suffice to say here that the idea of a 'community of care' (which, coincidentally, employed Healthco technology) was both appropriately simple (i.e. indisputable) and ambiguous (i.e. non-prescriptive) to appeal to multiple professional and occupational interests, and thus played an important role in mitigating potential resistance and developing cross-professional networks (cf. Clark and Salaman, 1995).

Finally, the Bankco case shows how the core project teams' activities failed to mobilize significant power either of process or meaning and, therefore, were unable to overcome local resistance or integrate knowledge across distributed groups. In relation to process power, the core team did hold events (e.g. international workshops, training events) aimed at enlisting support and integrating knowledge. However, each event involved, depending on availability, a different set of people and there was little attention to sustaining collaborative relations between events. In Bankco then, knowledge integration was addressed primarily through the discursive strategy of framing the innovation as 'Global KM'. Knowledge-sharing across business units was seen by the corporate project team as the rationale for the development of Intranet technology. However, this 'Global KM' vision did not relate well to the commercial interests of the different local businesses (e.g. the Domestic division).

Comparing the Bankco and Liftco cases, in particular, provides some interesting evidence on the role of technology in these political processes. As seen, a number of previous studies have highlighted the importance of the interpretive flexibility of technology in determining its use (Orlikowski, 1992). It is possible, 
then, to argue that the different technologies involved were important in influencing the success of the innovation process. For example, interpretive flexibility is, arguably, greater in the case of Intranets than ERP systems (a relatively mature technology) - whilst ERP has a relatively limited range of purposes, intranets can be used to a variety of different ends (Newell, 2001). Moreover, unlike intranet technology, a major feature of ERP is systems integration. Changes introduced by the technology, therefore inevitably cut across boundaries between functions and departments (e.g. sales, purchasing, distribution, finance - Lee \& Lee, 2000). It is possible, then, to argue that the ERP technology encouraged a more integrated pattern of use than did Intranet (Wilson et al., 1994).

However, analysis based on the designed properties of technological artefacts also needs to address the shaping effect of the practices through which these artefacts are applied (Orlikowski, 2000). In this light, the Bankco case seems to highlight the importance of the framing of the innovation process as an important influence on the practices surrounding the technology in use. More specifically, the core team at Bankco seemed to have defined the innovation process in terms of the broadcasting of a new idea (Knowledge Management) to the wider organization. Therefore, little care was taken in the selection of the individuals involved in the innovation activities, except insofar as the widest broadcast coverage was attained.

Significantly, for technological innovations of the kind reported here, which were highly dependent on knowledge integration, an important factor shaping the interpretation of the technology may be the implicit epistemological assumptions of key groups. In the Bankco case the prevailing view of the innovation process implied a content view of knowledge, focusing on its objective and transferable characteristics through IT. This can be contrasted with managers at Healthco and LiftCo whose words and actions imply a more relational view - that is, seeing 
knowledge as something produced by social interactions rather than broadcast through organizational channels

Finally, the comparison between the Healthco case and the other cases highlights the influence of the institutional context on networked innovations. This influence is not well captured by the forms of power discussed so far, and thus highlights the need to incorporate a further dimension of power in our analysis. This dimension - termed 'the power of the system' in Hardy's (1996) account reminds us that the other forms of power unfold within deeply institutionalized and taken for granted contexts which represent the 'backdrop' to innovation and which make it more or less likely to occur. As Foucault (1980) observes, the power of the system poses significant limitations on the ability of individuals to manage, or resist, change. For example, innovation that threatens to disrupt the deeply entrenched status and power of professions is very likely to meet with strong resistance (Drazin, 1990).

This perspective is particularly relevant to the comparison with the Healthco case, since the institutional context here was wider than in the other cases, encompassing inter-professional as well as inter-organizational relations. The relative power of some professional groups over others was deeply entrenched and reflected in well-established treatment regimes. This had important implications for the evolving interpretations of the innovation process. For example, whereas radiotherapists welcomed the new treatment because it gave them an opportunity to get directly involved in curing patients, consultant urologists were more likely to see it as a threat to their professional autonomy. This meant that, whilst inter-professional networks would coalesce around activities centred on the improving patient care, they would not support a focus on the technology per se. Previous research, has demonstrated the influence of the macro professional context on knowledge creation in innovation projects at the micro-level (Robertson et al., 2003). Whilst not a central focus, our findings suggest that such influences might also be at play here. Therefore future 
research might usefully address the mechanisms through which institutionalized systems of power and control shape the political influences on networked innovation.

\section{Conclusions}

Dougherty and Hardy (1996) argue that for organizations to become innovative they must 'reconfigure the power embedded in the organizational system - in its resources, processes and meanings'. The findings reported here provide support for that view of the politicality of innovation processes. However, by focusing on networked innovations they also help to extend that view in two ways. First, confirming previous research, the cases highlight the role of inter as well as intra-organizational networks in the innovation process (Jones et al., 2001) and the blurring of the two (Gittell and Weiss, 2004). However, in the context of networked innovation, the political dynamics are not only about the resource power of managers but also relate to the power effects of networks which extend inside and outside the innovating organization. Innovations which are dependent on knowledge integration across disparate groupings tend to shift the political emphasis away from the politics of stakeholder interest to the politics of process (how people form and co-ordinate networks) and the politics of meaning (how networks coalesce around particular interpretations).

Such innovations are not amenable to either top-down or bottom-up forms of management. Rather, this analysis suggests that understanding the politics of networked innovation depends on understanding the generative (and sometimes degenerative) relationship between power, knowledge integration, network formation and the role of technology. This relationship is schematically outlined in Figure 1, illustrating the contrast between the generative interplay of power, networks and knowledge integration found in the Healthco and Liftco cases, with the progressive unraveling of these same phenomena in Bankco. This comparison effectively underscores the important role of key actors in 
coordinating networks. Through effective network coordination, new sources of power - notably at the level of process and meaning - are created, which further reinforce the kinds of networking and knowledge integration which contribute to successful innovation outcomes. In this respect, Figure 1 also evokes the relationship between relative outcomes and the way in which the process of innovation unfolds in our cases. The importance of such processual features underlines the value of a qualitative analysis, and contrasts with the classical interest in the structural context of innovation (Burns and Stalker, 1961).

Finally, our analysis highlights the need to recognize the importance of the institutional context and the role of technology as important influences on networked innovation processes. This suggests a need for multi-level analyses, embracing not only the politics of the immediate innovation process but also the environing constellations of power invoked by technology and institutions. 


\section{References}

Alter, C., \& Hage, J. Organizations working together. 1993, Newbury Park, CA: Sage.

Barley, S. R. The alignment of technology and structure through roles and networks.. Administrative Science Quarterly, 1990, 35, 61-103.

Biernacki, P., \& Waldorf, D. Snowball Sampling - Problems And Techniques Of Chain Referral Sampling. Sociological Methods \& Research, 1981,10(2), 141-163.

Boland, R. J., \& Tenkasi, R. V. Perspective Making and Perspective Taking in Communities of Knowing. Organization Science, 1995 6(4): 350-363.

Brass D.J and Burkhardt E., Centrality and power in organizations. In N Nohria, R. G. Eccles (Eds.), Networks and organizations : structure, form, and action, 1992. 191-215. Harvard Business School Press: Boston, Mass.

Brown J. S. \& Duguid, P. Organizational learning and communities-of-practice: Towards a unified view of working, learning and innovation. Organization Science, 1991 2: 40-57

Brown, J. S., \& Duguid, P. Knowledge and organization: A social-practice perspective. Organization Science, 2001 12(2): 198-213.

Burns, T., \& Stalker, G. M., The Management of Innovation. 1961. London: Tavistock publications.

Callon, M. The state and technical innovation: A case study of the electrical vehicle in France. Research Policy, 1980 9: 358-376.

Carlile, P. R., A pragmatic view of knowledge and boundaries: Boundary objects in new product development. Organization Science, 2002, 13(4), 442-455.

Castells, M. The rise of the network society. 1996, Oxford: Blackwell.

Ciborra, C. U. From Control to Drift: The Dynamics of Global Information Infrastructures. 2000, Oxford: OUP. 
Clark, P., \& Staunton, N. Innovation in Technology and Organisation 1989.(London: Routledge.

Conway, S. Informal Boundary-Spanning Communication in the Innovation Process - an Empirical-Study. Technology Analysis \& Strategic Management, 1995, 7(3), 327-342.

Dougherty, D., \& Hardy, C. Sustained product innovation in large, mature organizations: Overcoming innovation-to-organization problems. Academy of Management Journal, 1996 39(5): 1120-1153.

Drazin, R. Professionals and innovation: Structural- functional versus radicalstructural perspectives. Journal of Management Studies, 1990, 27(3), 245 $-263$.

Eisenhardt, K. M. Building Theories from Case-Study Research. Academy of Management Review, 1989 14(4): 532-550.

Elg, U., \& Johansson, U. Decision making in inter-firm networks as a political process. Organization Studies, 1997,18 (3), 361-380.

Galaskiewicz, J. Exchange Networks and Community Politics. 1979. Beverly Hills, CA: Sage.

Garrety K and Badham R. The politics of socio-technical intervention: An interactionist view. Technology Analysis \& Strategic Management, 2000 12(1): $103-118$

Gittell, J. H., \& Weiss, L. Coordination networks within and across organizations:

A multi-level framework. Journal Of Management Studies, 2004, 41(1), 127-153.

Grandori A and Soda G. Inter-Firm Networks: Antecedents, Mechanisms and Forms. Organization Studies, 1995 16: 184-214

Granovetter, M. S. The strength of weak ties. American Journal of Sociology, 1973, 78, 1360-1380. 
Gulati, R. , Network location and learning: The influence of network resources and firm capabilities on alliance formation. Strategic Management Journal, 1999, 20(5), 397-420.

Gulati, R., Nohria, N., \& Zaheer, A. , Strategic networks. Strategic Management Journal, 2000, 21(3), 203-215.

Hakansson H, Havila V, Pedersen A.C. Learning in networks. Industrial Marketing Management, 1999 28(5): 443-452

Hansen M.T., The search transfer problem: The role of weak ties in sharing knowledge across organizational sub-units. Administrative Science Quarterly, 1999, 44: 82-111

Hardy, C. Understanding Power: Bringing about Strategic Change, British Journal of Management, 1996, Special Issue, 7, 1, S3-S16.

Hardy, C., Phillips, N., \& Lawrence, T. B. Resources, knowledge and influence: The organizational effects of interorganizational collaboration. Journal Of Management Studies, 2003, 40(2), 321-347.

Hickson, D. J., Hinings, C. R., Lee, C. A., Schneck, R. E. and Pennings, J. M. A strategic contingencies theory of intra-organizational power. Administrative Science Quarterly, 1971 16(2): 216-229.

Hislop, D. Newell, S., Scarbrough, H., \& Swan, J. Networks, knowledge and power: Decision making, politics and the process of innovation. Technology Analysis \& Strategic Management, 2000,12(3): 399-411.

Ibarra $\mathrm{H}$. Network centrality, power, and innovation involvement. Determinants of technical and administrative roles. Academy of Management Journal., 1993 36(3): 471-501

Inkpen, A. C.. Creating knowledge through collaboration. California Management Review, 1996, 39 (1), 123-140.

Jones, O., Conway, S., \& Steward, F. Social interaction and organisational change. 2001, London: Imperial College Press. 
Knights, D., \& Murray, F. Politics and Pain in Managing Information Technology a Case- Study from Insurance. Organization Studies, 1992,13(2), 211228.

Kreiner K, Schultz M. Informal collaboration in R \& D. The formation of Networks across Organizations. Organization Studies, 1993 14(2): 189-209

Krumbholz, M., Galliers, J., Coulianos, N., \& Maiden, N. A. M. Implementing enterprise resource planning packages in different corporate and national cultures. Journal of Information Technology, 2000 15(4): 267-279.

Latour, B. Science in Action. 1987, Milton Keynes: Open University Press.

Lave J, \& Wenger E. Situated Learning: Legitimate Peripheral Participation, 1991. Cambridge University Press: Cambridge

Lee, Z., \& Lee, J. Y. An ERP implementation case study from a knowledge transfer perspective. Journal of Information Technology, 2000 15(4): 281288.

Lukes S. Power: A radical view, 1974. Macmillan Press: London

Macdonald S.W. The informal network in an age of advanced telecommunications. Human Systems Management, 1993 11: 77-87

McLoughlin, I., Badham, R., \& Couchman, P. Rethinking Political Process in Technological Change: Socio-technical Configurations and Frames. Technology Analysis \& Strategic Management, 2000,12(1), 17.

Newell, S., Scarbrough, H., \& Swan, J. From global knowledge management to internal electronic fences: Contradictory outcomes of intranet development. British Journal of Management, 2001,12(2), 97-111.

Nonaka, I., \& Takeuchi, H. The Knowledge Creating Company 1995.(New York: Oxford University Press.

Okhuysen, G. A., \& Eisenhardt, K. M. Integrating knowledge in groups: How formal interventions enable flexibility. Organization Science, 2002 13(4): 370-386. 
Oliver, A. L., \& Ebers, M., Networking network studies: An analysis of conceptual configurations in the study of inter-organizational relationships. Organization Studies, 1998, 19 (4), 549-583.

Oliver, A. L., \& Liebeskind, J. P. Three levels of networking for sourcing intellectual capital in biotechnology. International Studies of Management and Organization, 1998, 27(4), 76-103.

Orlikowski, W. J. The duality of technology: Rethinking the concept of technology in organizations. Organization Science, 1992, 3(3), 398-427.

Orlikowski, W. J. Using technology and constituting structures: A practice lens for studying technology in organizations. Organization Science, 2000 11(4): 404-428.

Orlikowski, W. J., \& Gash, D. C. Technological Frames - Making Sense Of Information Technology In Organizations. Acm Transactions On Information Systems, 1994, 12(2), 174-207.

Owen-Smith, J., \& Powell, W. W., Knowledge Networks as Channels and Conduits: The Effects of Spillovers in the Boston Biotechnology Community. Organization Science, 2004, 15(1), 5-22.

Pettigrew A. M. Context and Action in the Transformation of the Firm. Journal of Management Studies, 1987 24(6): 649-670

Pettigrew, A. M. The Politics of Organisational Decision Making 1973.(London: Tavistock.

Phillips, N., Lawrence, T. B., \& Hardy, C. Inter-organizational collaboration and the dynamics of institutional fields. Journal of Management Studies, 2000, 37(1), 23-43.

Powell W, Koput, K. and Smith-Doerr, L. Interorganizational Collaboration and the Locus of Innovation: Networks of Learning in Biotechnology. Administrative Science Quarterly, 1996 41: 116-145 
Ring P. S and Van De Ven A. H. Developmental processes of cooperative interorganizational relationships. Academy of Management Review, 1994 19(1): 90-118

Robertson, M., Scarbrough, H., \& Swan, J. (2003). Knowledge creation in professional service firms: Institutional effects. Organization Studies, 24(6), 831-857.

Rogers E. M. Diffusion of innovations, 1983; 1995.( $3^{\text {rd }} \& 4$ th ed.). Free Press: New York

Scarbrough, H. (Ed.). The Management of Expertise.1996. Oxford: Blackwell.

Senker, J., \& Faulkner, W. Knowledge Frontiers: Public Sector Research and Industrial Innovation in Biotechnology, Engineering Ceramics and Parallel Computing 1995.(Oxford: Oxford University Press.

Smith-Ring, P. Processes facilitating reliance on trust in inter-organizational networks. In M. Ebers (Ed.), The Formation of Inter-Organizational Networks. 1997, Oxford: Oxford University Press.

Sturdy, A. The adoption of management ideas and practices - Theoretical perspectives and possibilities. Management Learning, 2004, 35(2), 155179.

Swan, J. A., Newell, S. and Robertson, M. Central agencies in the diffusion and design of technology: a comparison of the UK and Sweden. Organization Studies, 1999, 20, 905-932.

Swan, J., Scarbrough, H., \& Robertson, M. The construction of 'communities of practice' in the management of innovation. Management Learning, 2002, 33(4), 477-496.

Tidd J. Complexity, Networks and Learning: Integrative themes for research on innovation management. International Journal of Innovation Management, 1997 1(1): 1-21

Townley, B. Performance appraisal and the emergence of management. Journal of Management Studies, 1993 30(2): 221-238. 
Weick K. E. The Social Psychology of Organizing, 1979.(Addison-Wesley: Reading, Mass

Wilson, F., Desmond, J. \& Roberts, H. Success and failure of MRPII implementation. British Journal of Management, 1994, 5, 221-240.

Wolfe, R. A. Organisational innovation: review, critique and suggested research directions. Journal of Management Studies, 1994, 31, 405-431.

Yin RK. Case study research : design and methods, 1994.((2nd ed.). Sage Publications: Thousand Oaks 
Table 1: Cross Case Summary Analysis

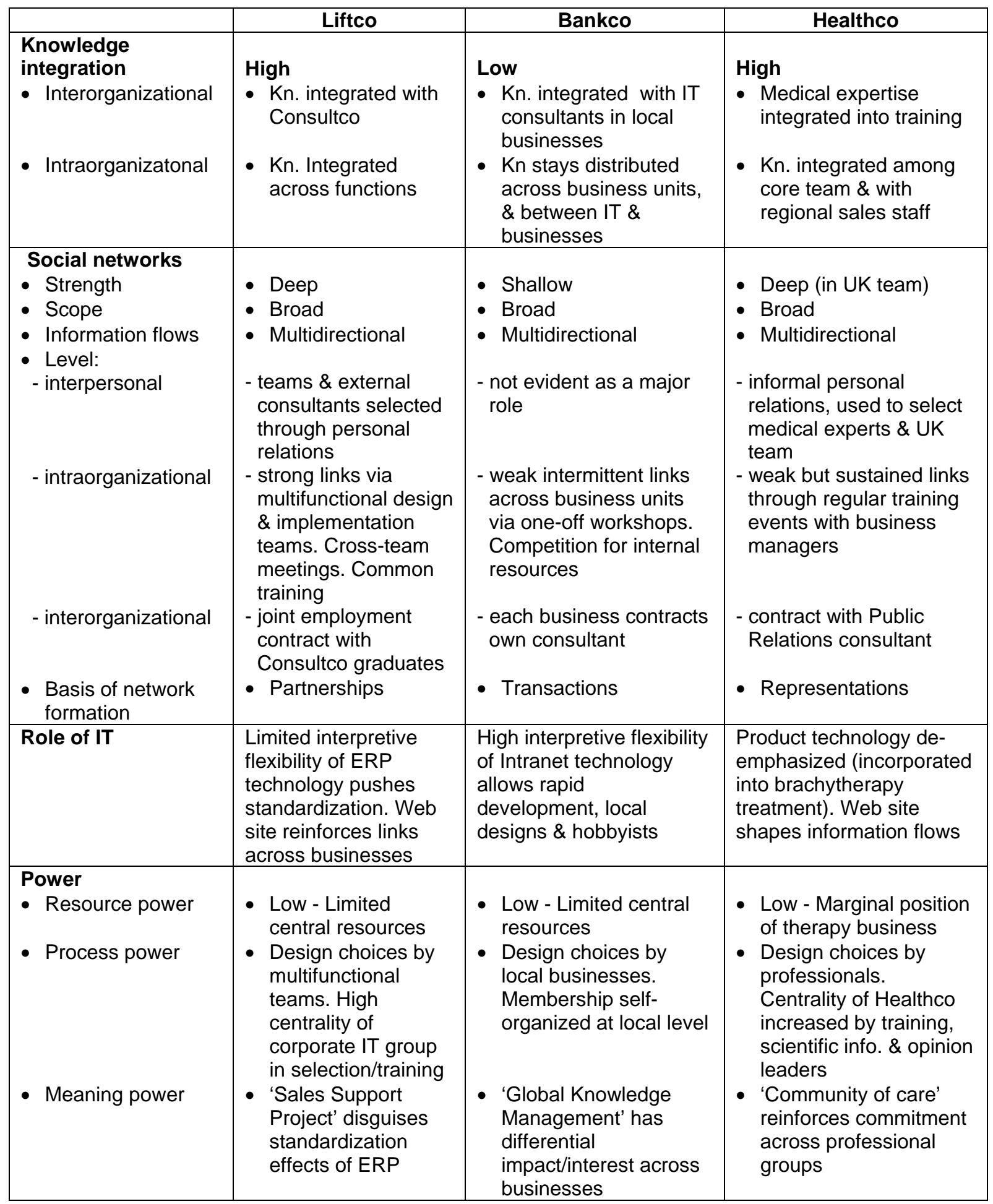


Figure 1: Generative interplay of power and networks in the innovation process

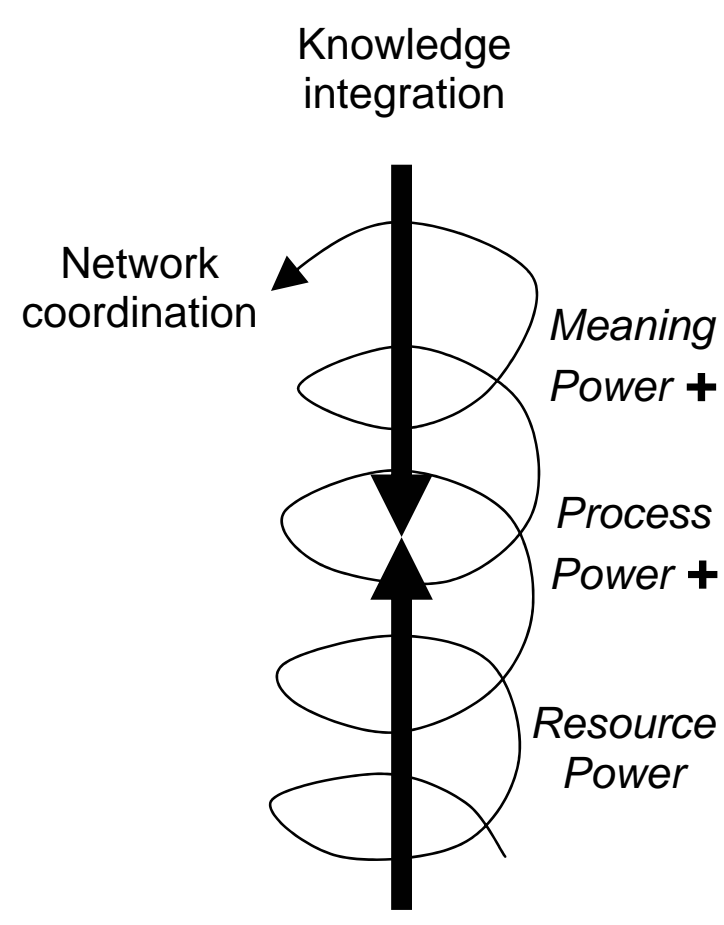

GENERATIVE EFFECTS:

Liftco and Healthco cases
Knowledge

disintegration

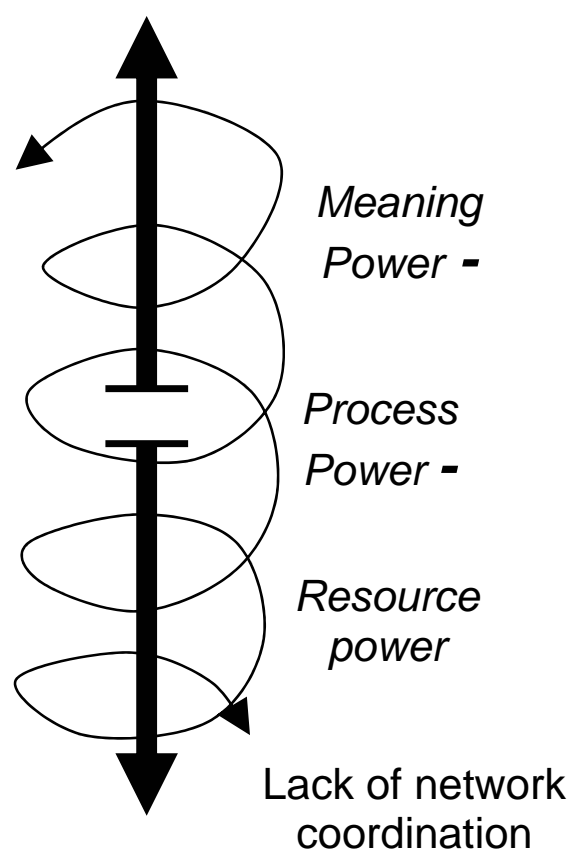

DEGENERATIVE EFFECTS

Bankco case 